\section{THU0002 IL-10 AND IL-6 POLYMORPHISMS ARE NOT RELATED TO EROSIVE DISEASE IN EARLY RHEUMATOID ARTHRITIS}

${ }^{1} \mathrm{C}$ Orellana, ${ }^{1} \mathrm{R}$ Sanmartí, ${ }^{1} \mathrm{JD}$ Cañete, ${ }^{2} \mathrm{~J}$ Yagüe, ${ }^{2} \mathrm{G}$ Ercilla, ${ }^{1} \mathrm{~A}$ Gómez, ${ }^{1} \mathrm{G}$ Salvador, 1J Muñoz-Gómez. 'Department of Rheumatology; ${ }^{2}$ Department of Immunology, Hospital Clínic, Barcelona, Spain

\subsection{6/annrheumdis-2001.105}

\section{Background}

Objectives To assess the prevalence of IL-10 and IL-6 polymorphisms in patients with early rheumatoid arthritis (RA) in our population and investigate whether there is an association with radiographic severity.

Methods 68 patients with early RA $(49 \mathrm{~F} / 19 \mathrm{M}$, mean age $51 \pm$ $15 \mathrm{y}$, mean disease duration $15 \pm 13 \mathrm{mo}, \mathrm{RF}+72 \%$, mean number of swollen joints at entry $8.23 \pm 7.33$ ). Patients were genotyped for HLA-DRB1 and IL-10 and IL-6 alleles and results compared with the control population $(\mathrm{n}=110)$. Hands and feet radiographs were taken at entry and then yearly during follow-up. The Larsen method was used to assess radiographic damage.

Results There were not differences in the distribution of IL-6 alleles in the RA patients compared with controls. A difference was found in the distribution of IL-10 polymorphism at position ?592 between patients with RA and the control population: 592CC, 592CA and 592AA were found in a 40\%, 54\% and 6\% of patients with RA versus a 55\%, 33\% and 12\% respectively among controls $(p=0.018)$. No other differences were found in the frequency of the IL-10 alleles between RA and controls. No associations related to IL- 6 or IL-10 polymorphisms were found in relation to radiographic damage.

Conclusion The IL-10 polymorphism at position ?592 showed a greater proportion of the CA allele in AR compared with the control population, although the clinical implications if any of this difference remains to be determined. No IL-6 nor any other IL-10 polymorphisms either were found to be associated to RA. No IL-10 nor IL-6 polymorphisms were found to be related to erosive disease in early rheumatoid arthritis.

\section{THU0003 ALTERED GENE EXPRESSION IN RHEUMATOID ARTHRITIS SYNOVIAL FIBROBLASTS AFTER FEW CULTURE PASSAGES}

${ }^{1} \mathrm{U}$ Müller-Ladner, ${ }^{1} E$ Neumann, ${ }^{1} \mathrm{M}$ Judex, ${ }^{1} \mathrm{~F}$ Kullmann, ${ }^{2} \mathrm{~J}$ Grifka, ${ }^{3} \mathrm{~K}$ Masuda, ${ }^{3} \mathrm{~S}$ Gay, 1f Schölmerich. 'Internal Medicine I; ${ }^{2}$ Department Orthopedics, University Hospital, Regensburg, Germany; ${ }^{3}$ Ctr Exp Rheum, Department Rheum, Zurich, Switzerland

10.1136/annrheumdis-2001.106

\section{Background}

Objectives Inflammation, synovial hyperplasia and articular destruction are typical features of rheumatoid arthritis (RA) pathophysiology modulated by activated synovial fibroblasts. To evaluate distinct metabolic pathways and gene expression, for the majority of experimental settings cultured RA synovial fibroblasts derived from synovial tissue samples are used. To analyse, whether RA synovial fibroblasts can be cultured for an extended period of time without changes in their gene expression pattern, a combination of RNA arbitrarily primed PCR (RAP-PCR) and cDNA array was used.

Methods RA synovial fibroblasts of 2 patients with RA were isolated and cultured under standard conditions for up to 9 passages. RNA was extracted from these cells after each of the passages 2-9. RAP-PCR was performed and the PCR reactions were hybridised to cDNA expression array membranes (Atlas ${ }^{\mathrm{TM}}$, Clontech). For gene expression analysis, cDNA expression array membranes with 190 tumour suppressor genes and oncogenes and 9 control genes were used. The gene expression pattern of RA samples after each passage was compared to the pattern of the previous and following passages.

Results RA synovial fibroblasts showed a stable cDNA expression pattern for passages 2 to 4 . After passages 5 to 6 , expression pattern started to change (approximately 5\% of the expressed genes). After passages 7 to 8 , expression pattern of more than $5 \%$ of the 190 analysed tumour suppressor genes and oncogenes were altered. Of these, oncogene (e.g. bcl-1) and tumour suppressor-associated gene (e.g. EB-1 and CDK tyrosine kinase) expression had changed. Of interest, cell proliferation and growth decreased after passages 6 to 7 but distinct oncogenes and tumour-suppressor genes (e.g. jun-B and bcl-1) were still found to be upregulated.

Conclusion The results of this study reveal that gene expression of cultured RA synovial fibroblasts starts to alter after few passages indicating that future experimental settings need to address this potential problem for interpretation of gene expression. In addition, the data support the hypothesis that lack of downregulation of oncogenes and tumour suppressor genes might be responsible for the long-term aggressive growth of RA synovial fibroblasts observed in RA joints.

\section{THU0004 ASSOCIATION BETWEEN HLA-DRB1 POLYMORPHISM AND MARKERS OF SEVERITY OF RHEUMATOID ARTHRITIS}

${ }^{1} \mathrm{JA}$ Stanczyk, ${ }^{2} \mathrm{~J}$ Hilt, ${ }^{1} \mathrm{G}$ Woszzzek, 'ML Kowalski. 'Department of Clinical Immunology; ${ }^{2}$ Division of Rheumatology, Medical University of Lodz, Lodz, Poland

\subsection{6/annrheumdis-2001.107}

Background It is now well established that genetic variations in HLA-DRB1 region may influence susceptibility to rheumatoid arthritis (RA). However genetic component of the disease severity has not been fully elucidated.

Objectives The goal of the study was to assess the association of the HLA-DRB1 gene with different markers of severity of the disease.

Methods Seventy six patients with RA and one hundred fifty two healthy controls were typed for HLA-DRB1 gene by molecular method (PCR-SSO). Clinical, radiographic and immunological assessment of patients was carried out. In order to compare disease progression in patients with different disease duration we introduced joint destruction index (JDI) defined as the number of eroded joints (II-IV ${ }^{\circ}$ Steinbrocker's stage) per years of the disease duration.

Results DRB1*04 alleles were present in 47\% of RA patients and in $25 \%$ healthy controls $\left(\mathrm{OR}=2,7 ; \mathrm{p}_{\mathrm{cor}}=0,01\right)$. The frequency of DRB1\%04 alleles was higher in patients with: 1) rheumatoid factor (RF) positive RA vs RF negative RA (OR $=14,9$; $\left.\mathrm{p}_{\text {cor }}=0,001\right) ; 2$ ) primarily chronic course of disease vs acute course of disease $\left(\mathrm{OR}=4,7 ; \mathrm{p}_{\mathrm{cor}}=0,03\right)$ and familial incidence of RA comparing to patients without familial history of RA (OR $\left.=7,8 ; \mathrm{p}_{\text {cor }}=0,02\right)$. DRB $1 * 04$ alleles were significantly more frequent in patients with more intensive joint destruction reflected by JDI equal or higher than $1\left(\mathrm{OR}=12,2 ; \mathrm{p}_{\mathrm{cor}}=\right.$ $0,001)$. We did not observed differences in frequencies of DRB1*01 alleles neither between patients and controls nor between subgroups of RA patients. 